\title{
Changing pattern of childhood blindness in Saudi Arabia
}

\author{
KHALID F TABBARA AND IHSAN A BADR \\ From the King Khaled Eye Specialist Hospital and Research Center, Riyadh, Saudi Arabia, and the \\ Francis I Proctor Foundation for Research in Ophthalmology and the Department of Ophthalmolgy, \\ University of California, San Francisco, USA
}

SUMMARY We studied 187 patients attending special educational institutions in Saudi Arabia who were blind before the age of 14 . All patients underwent complete ophthalmological evaluation. The visual acuity in $31 \%$ of the patients was no light perception and in $58 \%$ light perception to counting fingers at 3 feet $(1 \mathrm{~m}) .70 \%$ were blind before age 2 . Prior to 1962 acquired diseases led to blindness in $75 \%$ of the patients. From 1962 onwards genetically determined diseases accounted for $84 \%$ of childhood blindness. $56 \%$ of this group were the product of consanguineous marriages. On the other hand in the group who acquired blindness only $14 \%$ were from consanguineous marriages $(p<0.0001)$. We here describe guidelines for the prevention of childhood blindness in Saudi Arabia.

Blindness in children has been studied in different parts of the world. ${ }^{1-8}$ In general, malnutrition and infections are major factors and frequent causes of childhood blindness in many underdeveloped and developing countries. In developed countries genetically determined causes of childhood blindness are more prevalent than nutritional or infectious causes. Socioeconomic development and governmental programmes appear to help in eliminating these causes of blindness.

Statistical data about the causes of childhood blindness throughout Saudi Arabia, however, are not available. We therefore studied the causes of blindness among 187 Saudi students and assessed the changing pattern in the causation of childhood blindness in Saudi Arabia.

\section{Subjects and methods}

Subjects. One hundred and eighty-seven students attending two schools for the blind in Riyadh, Saudi Arabia, were examined. Students came from different parts of the country seeking education, which is subsidised by the Saudi government. We obtained individual histories from the medical charts at the

Correspondence to Dr K F Tabbara, Research Department, King Khaled Eye Specialist Hospital, PO Box 7191, Riyadh, Saudi Arabia 11462. schools, from the students themselves, or from parents.

Medical evaluation. We assessed the visual acuity and examined each student. All students underwent complete ophthalmological evaluation, including biomicroscopy and ophthalmoscopy. Ancillary ophthalmological testing, such as visual fields, $A$ and B scan, visual evoked response (VER), electrooculography(EOG), and electroretinography(ERG) were performed when indicated. In addition, students were seen by a paediatrician or an internist, depending on their age. Further laboratory testing was performed to corroborate the clinical findings and confirm the clinical impression. All examinations were carried out at the King Khaled Eye Specialist Hospital and Research Center in Riyadh, Saudi Arabia.

Criteria for inclusion in the study. One hundred and seventy of the 187 students examined were included in the study. Those included met the following three criteria: (1) The onset of blindness had occurred prior to the age of 14 years, (2) visual acuity was $20 / 200$ or less in the eye with the best correction, and (3) the patient was born and had resided in Saudi Arabia all of his/her life.

Statistical analysis. The $\chi^{2}$ test was used for statistical analysis of the data.

Age and sex. There were 108 male and 62 female 
Table 1 Age and sex distribution

\begin{tabular}{lclr}
\hline Age group & Male & Female & Total \\
\hline A. $<20$ years & $62(59 \%)$ & $43(41 \%)$ & 105 \\
B. 20 years and over & $46(71 \%)$ & $19(29 \%)$ & 65 \\
Total & 108 & 62 & 170 \\
\hline
\end{tabular}

students. The male to female ratio was $1 \cdot 7: 1$. Table 1 shows the age and sex distribution among the group studied. The group was divided into two subgroups: (A) patients born before 1962 (65 patients), and (B) patients born after 1962 (105 patients).

\section{Results}

Onset of blindness. Tables 2 and 3 depict the age of onset of blindness in patients born before and after 1962 respectively. Among the group born before $1962,18 \%$ became blind before the age of 2 years and $82 \%$ after that. This is in sharp contrast to the data showing that $70 \%$ of the patients born in or after 1962 were blind before the age of 2 years.

Visual acuity. Fifty-two students (31\%) had no light perception, $98(58 \%)$ had visual acuity ranging from light perception to counting fingers at 3 feet $(1 \mathrm{~m})$, and $20(11 \%)$ had a visual acuity varying between counting fingers at 3 feet (1 m) and 20/200.

Causes of blindness. Tables 4 and 5 show the causes of blindness among 163 Saudi students. The cause could not be determined among seven students; four were born prior to 1962 and three were born in or after 1962. One hundred and six students were blind from genetically determined diseases, and 57 students were blind from acquired diseases. Table 4 demonstrates the genetically determined diseases among 106 blind students. The diagnosis of genetic disorders was presumptive and based on the medical and family history and clinical findings.

Table 2 Age of onset of blindness in patients born before 1962

\begin{tabular}{llcl}
\hline Age of onset (years) & Male & Female & Total \\
\hline$<2$ & 9 & 3 & $12(18 \%)$ \\
$2-8$ & 19 & 12 & $31(48 \%)$ \\
$9-14$ & 18 & 4 & $22(34 \%)$ \\
Total & $46(71 \%)$ & $19(29 \%)$ & $65(100 \%)$ \\
\hline
\end{tabular}

Table 3 Age of onset of blindness in patients born in or after 1962

\begin{tabular}{lccc}
\hline Age of onset (years) & Male & Female & Total \\
\hline$<2$ & 40 & 33 & $73(70 \%)$ \\
$2-8$ & 18 & 9 & $27(26 \%)$ \\
$9-14$ & 4 & 1 & $5(4 \%)$ \\
Total & 62 & 43 & $105(100 \%)$ \\
\hline
\end{tabular}

Table 4 Genetic disorders among 106 blind students

\begin{tabular}{lll}
\hline Genetic disorders & $\begin{array}{l}\text { Born before } \\
1962\end{array}$ & $\begin{array}{l}\text { Born in or after } \\
1962 \\
\text { No. }(\%)\end{array}$ \\
& No. $(\%)$ \\
\hline Congenital cataract & $6(38)$ & $30(33)$ \\
Primary pigmentary degeneration & $1(6)$ & $26(29)$ \\
Congenital glaucoma & $4(25)$ & $14(16)$ \\
Leber's congenital amaurosis & - & $7(8)$ \\
Other causes & $5(39)$ & $13(15)$ \\
Total & $16(100 \%)$ & $90(100 \%)$ \\
\hline
\end{tabular}

Congenital cataract was the most frequently encountered genetic cause of blindness among both the group of students born before 1962 and those born in or after 1962. The evidence that the congenital cataract was genetically determined was presumptive and based on the family history, the inheritance pattern, and the absence of associated clinical findings that would suggest an in-utero acquired infection, a prenatal or perinatal disorder. Table 5 depicts the acquired causes of blindness before and in or after 1962. Among students who were born before $196291 \%$ of the causes of blindness were due to bilateral keratitis, subsequent corneal scarring, and/or perforation. Keratitis was due to bacterial corneal ulcers in 23 , smallpox in 16 , and measles in two students. No cases of smallpox leading to blindness could be detected in the group of students born after 1962. It is interesting that genetically determined causes accounted for blindness in 16 (25\%) of 65 students born before 1962 and 90 (86\%) out of 105 students born in or after 1962. There is a marked difference, in that acquired diseases (corneal infections, etc.) accounted for $60 \%$ of the causes of childhood blindness in the group born before 1962 and only $11 \%$ of the group born after 1962 $(\mathrm{p}<0.0001)$.

Family data. Among the students examined 67 out of 163 were the products of consanguineous marriages. Table 6 shows the correlation between the causes of childhood blindness and consanguinity among the parents. $56 \%$ of the students with genetically determined diseases were the product of consanguineous marriages compared with $14 \%$ in the students with acquired disorders.

Table 5 Acquired causes of childhood blindness in Saudi Arabia

\begin{tabular}{lcl}
\hline Acquired cases & $\begin{array}{l}\text { Born before 1962 } \\
\text { No. (\%) }\end{array}$ & $\begin{array}{l}\text { Born in or after } \\
1962 \text { No. (\%) }\end{array}$ \\
\hline Bacterial keratitis & $25(56)$ & $4(33)$ \\
Smallpox & $16(36)$ & $0(0)$ \\
Accidents & $2(4)$ & $7(58)$ \\
Other & $2(4)$ & $1(8)$ \\
Total & $45(100)$ & $12(100)$ \\
\hline
\end{tabular}


Table 6 Childhood blindness and parents' consanguinity

\begin{tabular}{lrc} 
& No. & Consanguinity* \\
\hline Genetically determined & 106 & $59(56 \%)$ \\
Acquired & 57 & $8(14 \%)$ \\
Total & 163 & 67 \\
\hline
\end{tabular}

${ }^{*} \mathrm{p}<0.0001$.

\section{Discussion}

As our study shows, most of these blind students are males. This is due to cultural factors. For instance, families give priority to boys for educational opportunities, and avoid sending their girls away from home. ${ }^{9}$ Furthermore, certain diseases such as Xlinked retinitis pigmentosa may lead to an increase in blindness among males.

The data obtained in this study indicates a changing pattern in the causes of childhood blindness in Saudi Arabia. There is a relative decrease in the incidence of corneal infections leading to blindness. After 1962 no smallpox keratitis leading to blindness could be detected. This is probably due to mass vaccination which has eradicated smallpox. In addition there was a corresponding decrease in the incidence of bacterial corneal ulcers as a cause of corneal perforation, endophthalmitis, and loss of the globe. This could be related to the recent economic improvements and to the dedication of the Saudi government in the delivery of health care.

Infectious trachoma is still highly prevalent in Saudi Arabia ${ }^{1011}$ and may lead to serious ocular complications and blindness in the adult population. In many instances we found evidence of active trachoma among the examined children, but trachoma was not incriminated as a direct cause of blindness in this age group. Childhood trachoma may lead to scarring of the palpebral conjunctiva, causing entropion and trichiasis. Persistent rubbing of the cornea by the eyelashes can lead to corneal abrasions, ulcerations, and secondary bacterial ulcers in adult life.

In the past two decades there has been an apparent

Table 7 Comparison of childhood blindness in four countries

\begin{tabular}{llllll}
\hline Aetiology & $\begin{array}{l}\text { England } \\
\text { and Wales }\end{array}$ & $\begin{array}{l}\text { Cyprus } \\
(\%)\end{array}$ & $\begin{array}{l}\text { Lebanon }^{2} \\
(\%)\end{array}$ & $\begin{array}{l}\text { Saudi Arabia: } \\
\text { present study (\%) }\end{array}$ \\
\cline { 4 - 6 } & & & & $\begin{array}{l}\text { Before } \\
1962\end{array}$ & $\begin{array}{l}\text { In or after } \\
1962\end{array}$ \\
\hline Hereditary & 50 & 79 & 77 & 25 & 84 \\
Prenatal & 6 & 4 & 1 & 3 & 1 \\
Perinatal & 33 & 2 & 2 & 0 & 1 \\
Postnatal & 11 & 15 & 20 & 66 & 11 \\
Unknown & - & - & - & 4 & 3 \\
\hline
\end{tabular}

decrease in the acquired causes of childhood blindness and a relative increase in the incidence of genetically determined causes. The preponderance of genetic diseases in the group born in or after 1962 coincides with reports from developed countries ${ }^{34}$ and appears to be different from other African, Asian, and Central American countries. ${ }^{6-8}$ Table 7 shows a comparison of the causes of childhood blindness among four countries. The mode of inheritance of the majority of genetic disorders in this group were autosomal recessive. The incidence of parental consanguinity among blind students with genetic diseases was significantly higher than among the parents of the students in the group with acquired diseases $(p<0.0001)$. It is a common and accepted tradition for marriages to be consanguineous. Marriages among cousins in Saudi Arabia are common and encouraged by the Arab family. In spoken Arabic the words for spouse and father-in-law are frequently interchangeable with cousin and uncle.

The segregation of blind students in special educational institutions provides a convenient framework for the study of childhood blindness. Such a study suffers from certain limitations, however. It excludes certain groups of patients who may suffer from blinding ocular disorders. For example, the mentally retarded, the partially sighted, the one-eyed, the deaf, and children of preschool age are not represented. Although the group investigated may not be representative of all blind children in Saudi Arabia, this study was successful in producing a balance sheet for the causes of childhood blindness in the Kingdom and in demonstrating a change in the pattern of causation. The overall rate of blindness cannot be assessed in this study. We therefore believe that a large-scale, statistically planned survey is indicated to evaluate the rate of childhood blindness in Saudi Arabia.

Table 8 shows suggested guidelines for the prevention of childhood blindness in Saudi Arabia. Eye examination at birth is of great importance in the prevention of blindness in childhood. The eye examination should be carried out by a paediatrician who

Table 8 Guidelines for the prevention of childhood blindness in Saudi Arabia

1. Eye examination at birth

2. Screening of preschool children

3. Early management of congenital cataract

4. Early management of glaucoma

5. A comprehensive programme of religious and governmental intervention to discourage marriage between persons having the same grandfather or grandmother

6. Genetic counselling

7. Vaccination for measles and rubella

8. Early detection and management of bacterial corneal ulcers

9. Mass treatment for trachoma 
is well informed about neonatal ocular disorders. Early detection of congenital cataracts and glaucoma should be followed by prompt treatment. Children with congenital cataracts should undergo surgical intervention and close postoperative follow-up for visual rehabilitation with corrective lenses. Similarly, congenital glaucoma should be treated early to prevent irreversible damage to the optic nerve. Screening of preschool children is aimed at the early detection of certain disorders such as ocular deviations and amblyopia. On the other hand consanguinity among married couples is a serious phenomenon in Saudi Arabia. This may explain the high prevalence of autosomal recessive disorders. Consanguineous marriages should be discouraged by systematic public education campaigns with the support of the religious authorities.

At present there are nine institutions for the visually handicapped in Saudi Arabia. The education of the children and young adults attending these institutions is fully subsidised by the Saudi government. Students are taught courses by braille and they are trained to acquire proficiency in certain manual skills such as pottery, handicrafts, weaving, etc. They are also trained to cope with their environment without help from the outside.
This study was supported by a grant from the King Khaled Eye Specialist Hospital and Research Center, Riyadh, Saudi Arabia.

\section{References}

1 Merin S, Lapithis AG, Horovitz D, Michaelson IC. Childhood blindness in Cyprus. Am J Ophthalmol 1972; 74: 538-42.

2 Baghdassarian SA, Tabbara KF. Childhood blindness in Lebanon. Am J Ophthalmol 1975; 79: 827-30.

3 Fraser GR, Friedman AI. The causes of blindness in childhood. A study of 766 children with severe visual handicaps. Baltimore: Johns Hopkins Press, 1967: 1-245.

4 Fraser GR. Causes of severe visual handicap among school children in Southern Australia. Med J Aust 1968; i: 61520.

5 Macdonald AE. Causes of blindness in Canada. Can Med Assoc $J$ 1965; 92: 264-79.

6 Quere MA. Ocular complications of measles as a major cause of blindness in children in tropical countries. Ophthalmologica 1964; 148: 107-20.

7 Olurin O. Etiology of blindness in Nigerian children. Am J Ophthalmol 1970; 70: 533-40.

8 Sommer A, Quesada J, Doty M, Faich G. Xerophthalmia and anterior-segment blindness among preschool-age children in El Salvador. Am J Ophthalmol 1975; 80: 1066-72.

9 Badr IA, Qureshi IH. Cause of blindness in the Eastern Province blind schools. Saudi Med J 1983; 4: 331-8.

10 Tabbara KR, Bobb AA. Lacrimal system complications in trachoma. Ophthalmology 1980; 87: 298-301.

11 Badr IA, Qureshi IH. Trachoma in Saudi Arabia. Saudi Med J 1982; 3: 53-6. 